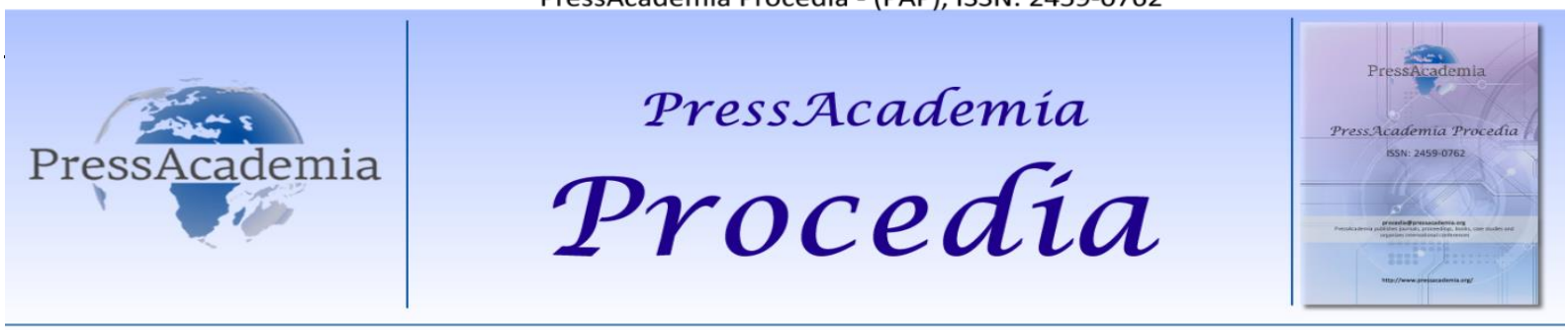

Global Business Research Congress (GBRC), May 24-25, 2017, Istanbul, Turkey.

\title{
THE EFFECT OF FOREIGN EXCHANGE VOLATILITY ON BROKERAGE FIRMS' REVENUE, EVIDENCE FROM TURKEY BETWEEN 2012-2016
}

DOI: 10.17261/Pressacademia.2017.403

PAP-GBRC-V.3-2017(18)-p.190-196

Oktay $\operatorname{Tas}^{1}$, Gokben Cevikcan ${ }^{2}$

${ }^{1}$ istanbul Teknik Üniversitesi, oktay.tas@itu.edu.tr

${ }^{2}$ istanbul Teknik Üniversitesi, gokbenaltas@gmail.com

To cite this document

Tas, O., G. Cevikcan (2017) The effect of foreign exchange volatility on brokerage firms' revenue, evidence from Turkey between 2012

2016, PressAcademia Procedia (PAP), V.3, p.190-196

Permemant link to this document: http://doi.org/10.17261/Pressacademia.2017.403

Copyright: Published by PressAcademia and limited licenced re-use rights only.

\begin{abstract}
Leveraged transactions, widely known as forex trading in Turkey is regulated by the Capital Markets Authority since August 2011 and only brokerage firms are allowed to trade in this industry. Employing the regression analysis, we investigate the effect of foreign exchange volatility on brokerage firms between 2012 and 2016. Our results indicate that, the volatility in foreign exchange rate have a significant positive effect on the revenue of forex trading of brokerage firms. The movements in the direction of foreign exchange rates have a bigger effect on the profit of brokerage firms.
\end{abstract}

Keywords: Over the counter capital markets, leveraged forex transactions, brokerage firms, foreign exchange movements.

JEL Codes: G20, G11, G23

\section{KUR HAREKETLERININ TÜRKIYE'DE KALDIRAÇLI FOREKS IŞLEMI YAPAN ARACI KURUMLARA ETKISI, 2012-2016}

\section{ÖZET}

Kamuoyunda "foreks" olarak bilinen kaldıraçlı alım satım işlemleri 2011 Ağustos ayından itibaren Sermaye Piyasası Kurulu'nun düzenlemelerine tabi olmaya başlamış ve bu işlemler bu tarihten itibaren yalnızca yetkili aracı kurumlarca yapılmaya başlamıştır. Döviz kurundaki hareketlerin, aracı kurumların kaldıraçlı işlemlerden elde ettiği gelirlere etkisinin regresyon analiziyle incelendiği bu çalışmada, volatilitenin aracı kurum gelirlerinde, pozitif yönde, anlamlı bir etkisi olduğu görülmüştür. Kurdaki volatilitenin yanı sıra kur yönündeki değişim sayısı da aracı kurum gelirlerinde önemli etkiye sahiptir. Söz konusu ilişkinin, aracı kurumların iş modellerine göre değişmesi de ayrıca irdelenmiştir. Tezgahüstü bir piyasa olan bu işlemlerde, piyasa yapıcısı konumundaki aracı kurumların gelir yapısı bu piyasada işlem yapan yatırımcı getirileri hakkında da ipucu vermektedir.

Anahtar Kelimeler: Tezgahüstü sermaye piyasaları, kaldıraçıı alım satım İşlemleri, aracı kurumlar, döviz kuru hareketleri JEL Kodları: G20, G11, G23 


\section{GiRiş}

Para birimlerinin değiştirilmesini ifade eden döviz işlemleri uluslararası ticaretin ve sermaye hareketlerinin temelini oluşturmaktadır. Son yıllarda geleneksel kullanımından farklı bir şekilde, hızla gelişen finansal piyasalara paralel olarak, kaldıracın kullanılabildiği döviz piyasası işlemleri uluslararası ticaret hacminden bağımsız, çok daha büyük bir piyasa haline gelmiştir. Uluslararası Ödemeler Bankası BIS'in yaptığı son ankete göre, tezgahüstü piyasalarda yapılan döviz işlemleri Nisan 2016 sonu itibariyle 5,1 trilyon \$’u aşmıştır (BIS, 2016).

Forex olarak adlandırılan bu işlemlerde iki ülke parasının birbirine ya da petrol, altın, gümüş, mısır, pamuk, kakao gibi emtia ve çeşitli endekslerin bir ülke parasına göre değeri alım satıma konu olmakta ve yatırımcılara yatırdıkları teminatın belirli bir katına kadar işlem yapma olanağı verilmektedir. Spot işlemlerin yanı sıra vadeli, swap ve opsiyon şeklindeki finansal araçlarla bu piyasada işlem yapılabilmektedir (Değertekin, 2010). Her ne kadar altın, petrol gibi emtialar dayanak kullanılsa da kaldıraçlı işlemlerde en önemli dayanak varlıklar EUR/USD gibi döviz kurlarıdır (Öztürk ve Toroslu. 2016).

24 saat işlem yapabilme özelliği olan foreks piyasasında işlem yapan taraflar merkez bankaları, ticari bankalar, yatırım fonları, hükümetler, uluslararası ticaret yapan şirketler, aracı kurumlar, bireysel yatırımcılar, kurumsal yatırımcılar olarak sıralanabilir (ISCI, 2011), (Nekritin \& Peters, 2012), (Wojcik, MacDonald-Korth, \& Zhao, 2014).

Özellikle internet erişiminin ve akıllı telefon kullanımının yaygınlaşması neticesinde bireysel yatırımcılar da foreks piyasasına kolaylıkla erişim imkanına kavuşmuş ve işlemler bu yatırımcı grubu açısından popüler bir yatırım aracı haline gelmiştir. Ayrıca bu işlemleri, tüm dünyada cazip kılan az miktardaki yatırımla yüksek tutarda işlem yapma olanağı, Türkiye'de yatırımcıların ilgisini çekmiştir. Türkiye'de düzenlemeler bu piyasada yatırımcılara yatırdıkları teminatın $100^{1}$ katına kadar işlem yapma olanağı vermektedir.

Daha önce yurtdışı kuruluşlar veya bu kuruluşların acenteleri üzerinden yapılan işlemler, 2011 Ağustos ayından itibaren Sermaye Piyasası Kurulu'nun düzenlemelerine tabi olmaya başlamıştır. Bu tarihten itibaren yalnızca aracı kurumlar bu işlemleri yapmaya yetkili kılınmıştır (SPK, 2011).

Özünde tezgahüstü bir piyasa olan bu piyasada, yurtdışında pek çok uygulamadan farklı olarak, yatırımcıların teminatı aracı kurum/yatırım kuruluşunun hesabından ziyade, Türkiye sermaye piyasalarında merkezi takas kuruluşu olan i̇stanbul Takas ve Saklama Bankası Takasbank'ta saklanmaktadır (IOSCO, 2016).

2016 yılsonu itibariyle piyasadaki teminatlı hesap sayısı 130.000 'i, yatırılan teminat miktarı da 300 milyon \$’ı aşmıştır (Takasbank, 2017). Aktif olarak işlem yapan müşteri sayısı da ivmelenerek artmış, 2016 yılında 40.000'i bulmuştur. 30 yıllık bir geçmişe sahip hisse senedi işlemlerinde aktif müşteri sayısının 200.000, 11 yıllık geçmişi olan vadeli işlem piyasasında 7.000 kişi civarındayken, 5 yıllık bir dönemde foreks piyasasında 40.000 aktif müşteri sayısına ulaşıması bu piyasanın dinamizminin bir göstergesidir. Doğal olarak, bu hızlı artışın arkasında yatırımcı ilgisinin yanı sıra, bu işlemi yapan kurumların reklam, çalışan, altyapı gibi ciddi yatırımlarının etkisi bulunmaktadır (TSPB, 2017a). Benzer şekilde, müşteriyle yapılan işlem hacmi 2016 yılında 3,5 trilyon \$ civarında (TSPB, 2017b) olup, bu işlemler yine hisse senedi ve vadeli işlemlerin epey üzerinde seyretmektedir.

\section{Tablo 1: Türkiye'de Foreks Piyasası}

\begin{tabular}{|l|r|r|r|r|r|}
\hline & $\mathbf{2 0 1 2}$ & $\mathbf{2 0 1 3}$ & $\mathbf{2 0 1 4}$ & $\mathbf{2 0 1 5}$ & $\mathbf{2 0 1 6}$ \\
\hline Teminatlı Hesap Sayısı & 11,543 & 29,709 & 51,377 & 94,305 & 121,564 \\
\hline İşlem Yapan Aktif Müşteri Sayısı & 7,261 & 13,674 & 21,296 & 34,304 & 40,713 \\
\hline Teminat Miktarı (Milyon \$) & 78 & 132 & 193 & 211 & 354 \\
\hline İşlem Hacmi (Müşteri, Milyon \$) & 795,485 & $1,545,819$ & $1,990,612$ & $3,491,986$ & $3,488,691$ \\
\hline İşlem Yapan Aracı Kurum Sayısı & 23 & 33 & 39 & 42 & 46 \\
\hline
\end{tabular}

Öte yandan, söz konusu işlemler, Türkiye'deki aracı kurumlar için de önemli bir faaliyet alanı haline gelmiştir. Nitekim, 2016 sonu itibariyle de aracı kurumların aracılık gelirlerinin yaklaşık yarısı bu piyasadaki işlemlerden elde edilmiştir (TSPB, 2017c). Bu kapsamda aracı kurumlar için bu piyasaya yönelik bir çalışmanın tüm taraflar için yararlı olacağı düşünülmektedir. Diğer ülkelerde olduğu gibi Türkiye'deki iş modelinde genellikle müşterinin aracı kurumda açtığı pozisyonun aracı kurum tarafından uluslararası alanda faaliyet gösteren ve anlaşmalı olunan bir likidite sağlayıcıda ters pozisyonla korunması yönündedir. Bu modelde aracı kurumun geliri likidite sağlayıcıdan aldığı kur kotasyonu (bid-ask spread) ile müşterisine verdiği kur kotasyonu arasındaki fark üzerinden ortaya çıkmaktadır. Öte yandan, bazı aracı kurumların iş modeli,

\footnotetext{
${ }^{1}$ Kaldıraçlı alım satım işlemlerine ilişkin, Şubat 2017'de çıkarılan bir düzenleme ile söz konusu kaldıraç oranları düşürülmüştür. Ancak, bu çalışma 2012-2016 dönemindeki aracı kurum ve yatırımcıları ele aldığı için söz konusu düzenlemelerin piyasaya etkisi kapsam dışında tutulmuştur.
} 
müşterilerin açmış olduğu pozisyonların aracı kurum portföyünden karşılanması, yani tam piyasa yapıcılık, üzerine kuruludur. Bu modelde, müşteri emirleri bir likidite sağlayıcıya aktarılmamaktadır.

Bu işlemlerin önemli bir kısmının döviz kurlarında yapıldığı göz önünde bulundurularak, bu çalışmada kurdaki hareketlerin ve işlem hacimlerinin aracı kurum gelirlerine etkisi irdelenmiştir. Tezgahüstü bir piyasa olan bu işlemlerde, piyasa yapıcısı konumundaki aracı kurumların gelir yapısı bu piyasada işlem yapan yatırımcı getirileri hakkında da ipucu vermektedir. Çalışmada bu hususa ilişkin değerlendirmeler de yapılmaktadır.

Çalışmanın girişinde foreks işlemleri ve Türkiye'deki piyasa hakkında genel bir bilgi verildikten sonra, ikinci bölümde konuyla ilgili literatür incelenmiş, ardından uygulama ve yöntem açıklanmıştır. Veri ve sonuçlar sunulduktan sonra son bölümde de bu sonuçlara ait değerlendirmeler yapılmıştır.

\section{LITERATÜR INCELEMESI}

Dünyada her ne kadar kaldıraçlı foreks işlemleri, finansal piyasalarda işlem hacmi olarak en yüksek paya sahip olmasına rağmen, literatürde diğer piyasalar göre bu işlemlere yönelik sayıca daha az çalışma mevcuttur (Heimer, 2016).

Gerek piyasa katılımcıları gerekse akademisyenler bu piyasaya ilişkin daha çok kur tahminleri üzerine çalışmalar yoğunlaşmış olup, çalışmaları teknik ve temel analiz olarak gruplandırmak mümkündür (Öztürk ve Toroslu, 2016). Temel analiz, milli gelir, cari açık, satın alma yöneticileri indeksi (PMI) ve diğer Merkez Bankası çıktıları gibi (Evans vd, 2013) makroekonomik faktörleri kullanarak fiyattaki değişimleri tahmin ederken, teknik analizde tarihi verileri kullanarak tahmin yürütülmeye çalışılır. Bu geleneksel yöntemlerin yanı sıra son on yıllarda literatürde "makine öğrenmesi" ve "yapay sinir ağları" metodlarındaki gelişimin ardından, bu yöntemlerin fiyat tahminlerinde de sıklıkla kullanılmaya başlamıştır (ör: Yuan, 2013; Zhang ve Ren, 2010; Evans vd., 2013).

Bununla birlikte, kaldıraçlı foreks işlemlerinde bireysel yatırımcılara yönelik son yıllarda çalışmalar hızlanmıştır. Heimer (2016), foreks yatırımcılarının, aktif hisse senedi yatırımcılarına benzer şekilde hareket ettiği bulgusunu ortaya koymuş, Ivanova vd. (2014) gibi pek çok araştırmacı da bu piyasadaki risk bazlı getirilerin hisse senedi piyasasından daha iyi olduğunu ortaya koymuştur.

Öte yandan, yazarların bildiği kadarıyla, bu piyasanın en önemli saç ayağı olan aracı kurumlar ve bu işlemlerden elde ettikleri gelirleri ile bu gelirleri etkileyen faktörlere ilişkin herhangi bir çalışma bulunmamaktadır. Giriş bölümünde değinildiği gibi, kaldıraçıı işlemler Türkiye'deki aracı kurumlar için önemli bir faaliyet alanı haline gelmiş, sadece bu alanda faaliyet gösteren yeni kurumlar kurulmaya başlamıştır.

\section{VERI VE YÖNTEM}

Bu çalışmada, aracı kurumların kaldıraçlı işlem gelirlerini etkileyen faktörler regresyon analizi yöntemiyle irdelenecektir. Bağımlı değişkenin aracı kurum gelirleri olarak kullanıldığı analizde, kaldıracı işlemlerde en fazla kullanılan ürün olan döviz kurundaki hareketleri ve yönü bağımlı değişken olarak kullanılacaktır. Her ne kadar aracı kurumlar, geleneksel hisse senedi işlemlerinde olduğu gibi işlem hacmine bağlı olarak komisyon elde etmese de, kontrol amaçlı işlem hacimleri de analize dahil edilecektir.

Çalışamada 2012-2016 yılları arasında Türkiye Sermaye Piyasaları Birliği'nin (TSPB) aracı kurumlardan üçer aylık dönemler itibariyle derlediği faaliyet ve finansal verileri kullanılmıştır. Yıllar içindeki enflasyon etkisini bertaraf edebilmek için Tüik'ten alınan TÜFE serileri kullanılmıştır. Aracı kurumların foreks işlemleri yapmaya yetkili kııındığı 20 çeyrek dönemi kapsayan çalışmada, döviz kurları Merkez Bankası alınmıştır. Döviz kurundaki oynaklığının temsili olarak Bloomberg'den TL/\$ Oynaklık Endeksi" de kullanılmıştır. Yapılan istatistiksel analizler Stata-13 programında elde edilmiştir.

\subsection{Durağanlık Testi}

Zamana göre dizilen serilerde değişkenler anlamlı bir ilişki olup olmadığı irdelenirken; verilerin doğal logaritmasının alınması sıklıkla kullanılan yöntemlerden biridir. Bu şekilde parasal ve oransal değişimlerin daha anlamlı şekilde karşılaştırılmasına imkân sağlanmaktadır (Çukur vd, 2012). Örneğin değişkenin incelenen dönemde 2 birimden 4 birime çıkması mutlak olarak 2 birimlik ve \%100'lük bir artışa denk gelmektedir. Öte yandan, aynı değişkenin 100 birimden 102 birime çıkması 2 birimlik mutlak artışa denk gelirken, oransal olarak \%2'lik bir artışa denk gelmektedir. Oysa doğal logaritması alınmış $2(0,69)$ ve 4 $(1,39)$ arasında 0,7 birim; doğal logaritması alınmış $100(4,61)$ ve $102(4,62)$ arasında yalnızca 0,01 birim artış vardır. Yani, her iki 2 birimlik artışın değişkenin zaman içerisindeki seyrine etkisi doğal logaritma ile daha net olarak gözlemlenebilmektedir. Bu kapsamda, yüzde hatta bindelik basamakta değişimlerin yaşandığı kur hareketlerinin karşılaştırıldığı gelir serisinin daha durgun/ durağan olması sağlanmaktadır. Serilerin doğal logaritması alınmasıyla, değişimlerin oransal marjinal katkısı belirlenebilmektedir. Ayrıca, uzun dönemli genel eğilimlerin (trend) olduğu serilerde, değişkenler arasında ilişki yanlış hesaplanabilmektedir. Serilerin doğal logaritmasının alınmasının, bu olumsuz etkiyi bertaraf edildiği yönde pek çok teorik ve ampirik çalışma mevcuttur (ör: Loutkepohl ve Xu, 2009; Çukur vd. 2012 gibi). 
Öte yandan, logaritması alınmış serilerin durağanlığın test edilmesi için Genişletilmiş Dickey-Fuller (Augmented Dickey Fuller) (ADF) testinin kullanılması benimsenmiştir. Değişkenlere ait uygun gecikme uzunluklarının belirlenebilmesi için Akaike Bilgi Kriteri (AIC) kullanılmıştır. ADF testi temel olarak aşağıdaki modele göre uygulanmaktadır.

$\Delta \mathrm{y}_{\mathrm{t}}=\alpha+\beta \mathrm{y}_{\mathrm{t}-1}+\sum_{\mathrm{i}=1}^{\mathrm{p}} \delta_{\mathrm{i}} \Delta \mathrm{y}_{\mathrm{t}-\mathrm{i}}+\mathrm{e}_{\mathrm{t}}$

Yukarıdaki denklemde y birim kök testin uygulanacağı değişkenleri (tablo 2'de yer alan foreks gelirleri, işlem hacmi, kur endeksi) $\alpha, \beta$ ve $\delta$ parametreleri, ortalaması sıfır ve değişen varyansa sahip hata terimlerini ifade etmektedir. ADF birim kök testinde $\beta$ parametresinin önemli olup olmadığına bakılmaktadır. Bir diğer ifadeyle $\beta=0$ boş hipotezi test edilmektedir.

\subsection{Regresyon Analizi}

Analizde kullanılacak veriler Tablo 2'de özetlenmiştir. Tablonun ikinci sütununda kurum başına ortalama foreks gelirleri (üç aylık) yer alırken, üçüncü sütunda müşteri ile yapılan kurum başına ortalama foreks işlemleri yer almaktadır. Her iki veri grubu da enflasyondan arındırılmıştır. İşlem hacimleri ve gelirleri sınırlı olan kurumlar analize dahil edilmemiştir.

Tablo 2: Aracı Kurumların Foreks Gelirleri ve Kur Hareketleri

\begin{tabular}{|c|c|c|c|c|c|c|}
\hline Dönem & $\begin{array}{l}\text { Ort. Foreks } \\
\text { Gelirleri (In) }\end{array}$ & $\begin{array}{l}\text { Ort. Foreks } \\
\text { İşlemleri (In) }\end{array}$ & $\begin{array}{l}\text { Kurun }^{1} \\
\text { Standart } \\
\text { Sapması }\end{array}$ & $\begin{array}{c}\text { Kur }^{1} \\
\text { Yönündeki } \\
\text { Değişim Sayısı } \\
\end{array}$ & $\begin{array}{c}\text { TL/\$ } \\
\text { Oynaklık } \\
\text { Endeksi }\end{array}$ & $\begin{array}{c}€ / \$ \text { Gün İçi En } \\
\text { Yüksek En Düşük } \\
\text { Fiyat Farkı }\end{array}$ \\
\hline 2012Ç1 & 15.2 & 24.5 & $1.7 \%$ & 31 & 11.0 & $1.3 \%$ \\
\hline $2012 C ̧ 2$ & 15.0 & 24.5 & $0.8 \%$ & 28 & 10.3 & $1.1 \%$ \\
\hline $2012 C ̧ 3$ & 14.4 & 24.5 & $1.2 \%$ & 26 & 8.7 & $1.1 \%$ \\
\hline $2012 C ̧ 4$ & 14.5 & 24.1 & $0.7 \%$ & 23 & 5.5 & $0.8 \%$ \\
\hline 2013Ç1 & 14.5 & 24.3 & $0.6 \%$ & 22 & 5.8 & $1.1 \%$ \\
\hline $2013 C ̧ 2$ & 15.0 & 24.3 & $2.8 \%$ & 27 & 8.8 & $1.1 \%$ \\
\hline $2013 C ̧ 3$ & 14.7 & 24.4 & $2.7 \%$ & 26 & 8.2 & $0.9 \%$ \\
\hline $2013 C ̧ 4$ & 15.0 & 24.3 & $2.1 \%$ & 23 & 10.8 & $0.8 \%$ \\
\hline 2014Ç1 & 14.9 & 24.2 & $1.6 \%$ & 32 & 14.8 & $0.8 \%$ \\
\hline $2014 C ̧ 2$ & 14.5 & 24.3 & $1.1 \%$ & 25 & 9.2 & $0.6 \%$ \\
\hline $2014 C ̧ 3$ & 14.9 & 24.5 & $1.0 \%$ & 35 & 9.7 & $0.6 \%$ \\
\hline $2014 C ̧ 4$ & 15.2 & 24.8 & $1.6 \%$ & 32 & 10.0 & $1.0 \%$ \\
\hline 2015Ç1 & 15.4 & 25.0 & $3.0 \%$ & 31 & 14.4 & $1.4 \%$ \\
\hline $2015 C ̧ 2$ & 15.0 & 24.9 & $2.4 \%$ & 25 & 14.6 & $1.4 \%$ \\
\hline $2015 C ̧ 3$ & 15.3 & 25.0 & $5.4 \%$ & 31 & 14.6 & $1.2 \%$ \\
\hline $2015 C ̧ 4$ & 15.4 & 25.1 & $2.2 \%$ & 29 & 13.3 & $1.0 \%$ \\
\hline 2016Ç1 & 15.4 & 25.0 & $1.4 \%$ & 29 & 11.0 & $1.1 \%$ \\
\hline $2016 C ̧ 2$ & 15.1 & 25.1 & $1.7 \%$ & 32 & 10.4 & $0.9 \%$ \\
\hline $2016 C ̧ 3$ & 14.7 & 24.9 & $1.4 \%$ & 30 & 10.4 & $0.7 \%$ \\
\hline $2016 C ̧ 4$ & 15.7 & 25.1 & $2,8 \%$ & 31 & 10.5 & $0,8 \%$ \\
\hline
\end{tabular}

: Kur göstergesi olarak, ABD doları ve avronun eşit ağırlıklandırılarak hesaplanan sepet kullanıımıştır

Foreks işlemlerinin önemli bir kısmı ABD doları ve avro kurlarını baz aldığı için, bu para birimlerindeki hareket aracı kurumların foreks gelirlerindeki harekete de yön vermektedir. Tablonun dördüncü sütununda $0.5 \$$ ve $0.5 €^{\prime}$ dan oluşan kur sepetinin ilgili üç aydaki oynaklığı verilmiştir. Oynaklık göstergesi olarak, kur sepetinin gün sonu değerlerinin ilgili üç aydaki standart sapması, diğer bir deyişle ortalama etrafındaki hareketlerin ortalaması esas alınmıştır.

Tablonun beşinci sütununda "Kur Yönündeki Değişim Sayısı" başlığı altında yer alan veriler, ilgili dönem içinde kur sepetinin kaç defa yön değiştirdiğine ilişkin bilgi vermektedir. Bir gün öncesine göre aynı yönde hareket eden (artan veya azalan) kur, ertesi gün farklı yönde hareket ederse, yön değiştirmiş, bir anlamda oynaklık yaratmış kabul edilmektedir. Aynı yönde hareket ederse, oynaklık hesabında dikkate alınmamaktadır. Tablodaki tutarlar, ilgili dönem içinde oynaklık olarak kabul edilen hareketlerin toplamını yansıtmaktadır.

Tablonun son iki sütununda kur hareketlerine/oynaklığına ilişkin alternatif göstergeler kullanılmış, modelde ayrı ayrı kullanılmıştır. Altıncı sütununda "TL/\$ Oynaklık Endeksi" başlığında piyasa tarafından yakından takip edilen ve Bloomberg tarafından hesaplanan "USDTRYV1M" kodlu örtülü oynaklık (implied volatility) endeksi gösterilmektedir. Tabloda aylık olarak açıklanan endeksin, ilgili çeyreklerdeki ortalamasına yer verilmiştir. Tablonun son sütununda ise, foreks işlem hacimlerinde önemli paya sahip olduğu bilinen $€ / \$$ paritesinin, gün içindeki en yüksek ve en düşük değeri arasındaki farka 
ilişkin bilgi verilmektedir. Piyasada bir çeşit oynaklık göstergesi olarak kullanılabilen bu veriler, ilgili çeyrekteki gün içi farkların ortalamasını yansıtmaktadır.

Regresyon analizi aşağıdaki gibi kurgulanmıştır.

$\mathrm{G}_{\mathrm{t}}=\mathrm{a}_{0}+\mathrm{a}_{1} \mathrm{H}_{\mathrm{t}}+\mathrm{a}_{2} \mathrm{~K}_{\mathrm{t}}+\mathrm{a}_{3} \mathrm{D}_{\mathrm{t}}+\mathrm{u}_{\mathrm{t}}$

Modelde,

$\mathrm{G}_{\mathrm{t}}$, ilgili zaman dilimindeki aracı kurum başına ortalama foreks geliri,

$\mathrm{H}_{\mathrm{t}}$, ilgili zaman dilimindeki aracı kurum başına ortalama işlem hacmi

$\mathrm{K}_{\mathrm{t}}$, ilgili zaman dilimindeki kur sepetindeki oynaklık ( $€$ ve \$'dan oluşan kur sepetinin standart sapması, TL/\$ oynaklık endeksi ve $€ / \$$ en yüksek-en düşük değer farkı ayrı ayrı modele dahil edilmiştir ${ }^{2}$ )

$D_{t}$, ilgili zaman dilimindeki Kur Yönündeki Değişim Sayısını göstermektedir.

Burada $\alpha$ ve $\beta i=1,2,3$ ortalama denklemin parametrelerini; ut ve vt hata terimlerini ifade etmektedir. Model En Çok Benzerlik Metoduyla tahmin edilmeye çalışılmıştır.

\section{BULGULAR}

\subsection{Birim Kök Sonuçları}

Tablo 3'te birim kök test sonuçları özetlenmiş olup, ele alınan serilerin ADF istatistiği MacKinon kritik değerinin üzerinde çıkmış, yani durağan olduğu kanıtlanmıştır. Sonuç itibariyle 0. derecede gelir, işlem hacmi ve kur hareketleri serileri durağan bulunmuştur.

Tablo 3: Birim Kök Test Sonuçları

\begin{tabular}{|l|r|r|}
\hline & ADF İstatistiği & Kritik Değer* \\
\hline G (Gelir) & -26.7313 & -3.4337 \\
\hline $\mathrm{H}$ (Hacim) & -13.4357 & -3.4337 \\
\hline$K_{1}$ (kur standart sapması) & -22.453 & -3.4337 \\
\hline$K_{2}$ (kur oynaklık endeksi) & -11.1589 & -3.4337 \\
\hline$K_{3}$ (kur en yüksek en düşük fark) & -12.1546 & -3.4337 \\
\hline$D$ (kurdaki yön sayısı) & -4.1678 & -3.4337 \\
\hline
\end{tabular}

*MacKinnon kritik değerleri

\subsection{Regresyon Sonuçları}

Değişkenlere ilişkin durağanlık varsayımı sağlandıktan sonra, aracı kurumların foreks gelirleri ile kur hareketleri arasındaki ilişkiyi belirleyebilmek için yapılan regresyon analizlerin sonuçları aşağıda gösterilmiştir.

Aracı kurumların foreks gelirleri ile, kur hareketleri için kullanılan göstergeler arasındaki ilişki ayrı ayrı sınanmıştır. Tablo 4, 5 ve $6^{\prime}$ da sınanan modellerin \%95 güven aralığında sonuçları özetlenmektedir. Üç modelin p değeri 0,05'ten düşük çıkmış, modeller anlamlı olmuştur. Bu kapsamda, kur oynaklığının arttığı zamanlarda aracı kurumların gelirlerinin arttığını genelleştirmek ve yorumlamak mümkündür.

Tablo 4: Model 1: Foreks Gelirleri ile Kur Hareketlerindeki (€/TL Kur Sepeti Oynaklığı) iliş̧ki

\begin{tabular}{|c|c|c|c|}
\hline $\mathbf{G}_{\mathrm{t}}$ & Katsayı & Standart Sapma & P Değerleri $(\mathrm{P}>\mathrm{t})$ \\
\hline$\alpha_{o}$ & 0.0004 & 0.000360 & 0.324 \\
\hline$\alpha_{1}\left(H_{t}\right)$ & 0.3212 & 0.001228 & 0.000 \\
\hline$\alpha_{2}\left(K_{t}\right)$ & 0.3872 & 0.001569 & 0.000 \\
\hline$\alpha_{3}\left(D_{t}\right)$ & 0.2312 & 0.017895 & 0.060 \\
\hline \multicolumn{4}{|c|}{ Denklem : $\mathrm{G}_{\mathrm{t}}=\alpha_{\mathrm{o}}+\alpha_{1} \mathrm{H}_{\mathrm{t}}+\alpha_{2} \mathrm{~K}_{\mathrm{t}}+\alpha_{3} \mathrm{D}_{\mathrm{t}}+\mathrm{u}_{\mathrm{t}}$} \\
\hline \multicolumn{2}{|l|}{ Gözlem sayısı } & \multicolumn{2}{|l|}{20} \\
\hline \multicolumn{2}{|l|}{$P$ değeri $(P>F)$} & \multicolumn{2}{|l|}{0.0000} \\
\hline \multicolumn{2}{|l|}{$\mathrm{R}^{2}$} & \multicolumn{2}{|l|}{0.3762} \\
\hline
\end{tabular}

2 Üç farklı kur oynaklık göstergesi arasında doğrusal bir ilişki olabileceği nedeniyle, üçünün aynı anda tek bir modelde açıklayıcı değişken olarak kullanılması ile modelde çoklu doğrusallık problemini (multicollinearity) ortaya çıkacağı için üç değişken de ayrı ayrı değerlendirilmiştir. 
Kurdaki oynaklığın göstergesi olarak kur sepetindeki standart sapmaların kullanıldığı 1. regresyon modelin sonuçları Tablo 4'de verilmiştir. Değişkenlere tek tek bakıldığında ise, işlem hacimlerindeki 1 birimlik artışın gelirler üzerinde 0,3'lük bir artışa neden olurken, kurların ortalama standart sapma üzerindeki 1 birimlik artışın gelirlerde daha yüksek artışa işaret etmesi dikkat çekmektedir. Kur yönündeki değişim sayısı ile aracı kurumların kaldıraçıı işlem gelirleri arasında anlamlı bir ilişki söz konusudur.

Altrernatif kur oynaklığı göstergeleri ile gelir arasındaki ilişkiler Tablo 5 ve $6^{\prime}$ da sunulmuş olup, ilk modelle çok önemli bir değişim söz konusu değildir. Yine de, kur oynaklığı göstergesi olarak kullanılan ikinci model, TL/\$ Oynaklık Endeksinin $\mathrm{R}^{2}$ i en yüksek çıkmış olup, özellikle son yılda TL/\$ kurundaki hareketlerin piyasaya yön verdiğini söylemek mümkündür.

Tablo 5: Model 2: Foreks Gelirleri ile Kur Hareketlerindeki (TL/\$ Kuru Oynaklık Endeksi) ilişki

\begin{tabular}{|l|r|r|r|}
\hline$G_{t}$ & Katsayı & Standart Sapma & P Değerleri (P>t) \\
\hline$\alpha_{0}$ & 0.0002 & 0.000189 & 0.289 \\
\hline$\alpha_{1}\left(H_{t}\right)$ & 0.3518 & 0.01315 & 0.000 \\
\hline$\alpha_{2}\left(K_{t}\right)$ & 0.4212 & 0.01329 & 0.000 \\
\hline$\alpha_{3}\left(D_{t}\right)$ & 0.2156 & 0.01645 & 0.060 \\
\hline Denklem : $G_{t}=\alpha_{o}+\alpha_{1} H_{t}+\alpha_{2} K_{t}+\alpha_{3} D_{t}+U_{t}$ & & \\
\hline Gözlem sayıSI & & 20 & \\
\hline$P$ değeri (P> F) & 0.0000 & \\
\hline$R^{2}$ & & & \\
\hline
\end{tabular}

Tablo 5: Model 2: Foreks Gelirleri ile Kur Hareketlerindeki (€/\$ en yüksek-endüşük fark) ilişki

\begin{tabular}{|c|c|c|c|}
\hline$G_{t}$ & Katsayı & Standart Sapma & $P$ Değerleri $(P>t)$ \\
\hline$\alpha_{\circ}$ & 0.0012 & 0.000152 & 0.386 \\
\hline$\alpha_{1}\left(H_{t}\right)$ & 0.2516 & 0.01426 & 0.000 \\
\hline$\alpha_{2}\left(K_{t}\right)$ & 0.1718 & 0.01425 & 0.000 \\
\hline$\alpha_{3}\left(D_{t}\right)$ & 0.1123 & 0.01346 & 0.060 \\
\hline \multicolumn{4}{|c|}{ Denklem : $\mathrm{G}_{\mathrm{t}}=\alpha_{\mathrm{o}}+\alpha_{1} \mathrm{H}_{\mathrm{t}}+\alpha_{2} \mathrm{~K}_{\mathrm{t}}+\alpha_{3} \mathrm{D}_{\mathrm{t}}+\mathrm{u}_{\mathrm{t}}$} \\
\hline \multicolumn{2}{|l|}{ Gözlem sayısı } & \multicolumn{2}{|l|}{20} \\
\hline \multicolumn{2}{|l|}{$P$ değeri $(P>F)$} & \multicolumn{2}{|l|}{0.0000} \\
\hline \multicolumn{2}{|l|}{$\mathrm{R}^{2}$} & \multicolumn{2}{|l|}{0.2156} \\
\hline
\end{tabular}

\section{SONUÇ}

2011 tarihinde SPK'nın düzenlemesine giren ve sadece aracı kurumların işlem yapabildiği foreks piyasası, aracı kurumlar için yeni bir faaliyet alanı olmuş, bu kurumların gelir çeşitliliğini artırmasına katkı sağlamıştır. Kısa vadeli risklerin çok yüksek olduğu bu piyasada aracı kurumların gelirleri de önemli ölçüde değişkenlik göstermiştir. Geleneksel hisse senedi ya da tahvil piyasasından farklı olarak, aracı kurumların foreks işlemlerinden elde ettiği gelirlerin, işlem hacimlerindeki değişimden ziyade fiyat (kur) hareketlerinden etkilendiği görülmüştür. 


\section{KAYNAKÇA}

Altan, M., GÜZEL, F. (2015), Forex Piyasasının Türkiye'deki Durumu ve Türkiye Finans Piyasalarına Etkileri, Journal of Institute of Social Sciences Vol: 33, 2015 ss. 203-214

Alessandri, T., Cerrato, D., Depperu, D. (2014). Organizational slack, experience and acquisition behavior across varying economic environments. Management Decision, vol. 56, no. 5, p. 967-982.

B.F.I.S.-M.E. Department, Foreign Exchange Turnover in April 2016: Preliminary Global Results, Technical Report, Bank For International Settlements (2016) $\underline{\text { d }}$ adresinden alındı

Çukur, S., Gümrah, Ü. ve Üstün Gümrah, M. (2012). İstanbul Menkul Kıymetler Borsasında hisse senedi getirileri ve işlem hacmi ilişkisi. Niğde Üniversitesi iïBF Dergisi, 5 (1): 20-35.

Değertekin, E. A. (2010, Nisan). Döviz Piyasaları. Sermaye Piyasasında Gündem(92), TSPB, s. 8-17.

Evans, C., Pappas, K., Xhafa, K. Utilizing artificial neural networks and genetic algorithms to build an algo-trading model for intra-day foreign exchange speculation, Mathematical and Computing Modelling, Vol.58, p.1249-1266

H. Zhang, R. Ren, (2010) High frequency foreign exchange trading strategies based on genetic algorithms, in: Proc. Second Int Networks Security Wireless Communications and Trusted Computing (NSWCTC) Conf, Vol. 2, pp. 426-429.

Heimer, Rawley, Can Leverage Constraints Make (Some) Investors Better Off? (September 12, 2016). Available at SSRN: https://ssrn.com/abstract=2150980 or http://dx.doi.org/10.2139/ssrn.2150980

Internatıonal Organızatıon Of Securıtıes Commıssıons (2016) Report on the IOSCO Survey on Retail OTC Leveraged Products

ISCI. (2011,). Financial Treasury and FOREX Management. Noida, India: The Institute of Company Secretaries of India - ISCI.

Ivanova, Y., Neely, C. J., Rapach, D. E., and Weller, P. A. (2014). Can risk explain the profitability of technical trading in currency markets? Federal Reserve Bank of St. Louis, Working Paper.

Nekritin, A., \& Peters, W. (2012). Naked FOREX: High-Probability Techniques for Trading without Indicators. Haboken, New Jersey, USA: John Wiley \& Sons.

Owens, S. (2004, July). The FOREX Report: The Six Forces of Forex. Aralık 16, 2014 tarihinde FX Engines, Inc.: www.fxengines.com adresinden alınd

SPK. (2011) Kaldıraçlı Alım Satım İşlemleri ve Bu İşlemleri Gerçekleştirebilecek Kurumlara illişkin Esaslar Hakkında Tebliğ. (125), Seri: V. Resmi Gazete.

Ozturk, M. Toroslu H. Fidan G. (2016) Heuristic Based Trading System On Forex Data Using Technical İndicator Rules, Applied Soft Computing, Vol. 43, p. 170-186

Takasbank, 2017, Kaldıraçlı Alım Satım İşlemlerine illişin Veriler, https://www.takasbank.com.tr/tr/Sayfalar/IstatistikiBilgiler.aspx adresinden alındı.

Tükiye Sermaye Piyasaları Birliği, 2017a, Foreks Kurumları ve Aracı Kurumlar, Gösterge Sayı 11

Tükiye Sermaye Piyasaları Birliği, 2017b, Sermaye Piyasası Özet Verileri, https://www.tspb.org.tr/veriler/ adresinden alındı.

Tükiye Sermaye Piyasaları Birliği, 2017c, Aracı Kurumların 2016 Sektör Analizi, Gösterge Sayı 12

Wojcik, D., MacDonald-Korth, D., \& Zhao, S. X. (2014, September). The Geography of Foreign Exchange Trading: Currencies and International Financial Centres. December 16, 2014 tarihinde Social Science Research Network (SSRN): http://papers.ssrn.com/sol3/papers.cfm?abstract_id=2501285 adresinden alındı.

Yıldırım, A. (2013),Gerçek yatırımc 215 bin yatırımın vadesi 1.5 ay, Bloomberg http://www.bloomberght.com/ht-yazarlar/abdurrahmanyildirim/1366748-gercek-yatirimci-215-bin-yatirimin-vadesi-15-ay/ adresinden erişildi.

Y. Yuan, (2013) Forecasting the movement direction of exchange rate with polynomial smooth support vector machine, Mathematical and Computer Modeling, Vol. 57 p.932-944. 